\title{
Radiation proctitis
}

INSERM

\section{Source}

INSERM. (1999). Orphanet: an online rare disease and orphan drug data base. Radiation proctitis. ORPHA:70475

Radiation proctitis is a rare rectal disease directly induced by pelvic radiotherapy and characterized by rectal bleeding, change in bowel habits, tenesmus and sepsis. 